\title{
Personal Fine Particulate Matter Constituents, Increased Systemic Inflammation, and the Role of DNA Hypomethylation
}

\author{
Xiaoning Lei ${ }^{\dagger}$, Renjie Chen ${ }^{\dagger}$, Cuicui Wang ${ }^{\dagger}$, Jingjin Shi ${ }^{\dagger}$, Zhuohui Zhao ${ }^{\dagger}$, Weihua $\mathrm{Li}^{\ddagger}$, \\ Beizhan Yan ${ }^{\S}$, Steve Chillrud ${ }^{\S}$, Jing Cai ${ }^{*}, \dagger$, , Haidong Kan ${ }^{*}, \dagger, \ddagger$ \\ tSchool of Public Health, Key Lab of Public Health Safety of the Ministry of Education and NHC \\ Key Laboratory of Health Technology Assessment, Fudan University, Shanghai, 200433, China \\ ¥Key Laboratory of Reproduction Regulation of National Population and Family Planning \\ Commission, Shanghai Institute of Planned Research, Institute of Reproduction and \\ Development, Fudan University, Shanghai, 200433, China \\ §Division of Geochemistry, Lamont-Doherty Earth Observatory of Columbia University, Palisades, \\ New York 10964, United States \\ "Shanghai Key Laboratory of Meteorology and Health, Shanghai, 200030, China
}

\section{Abstract}

Limited evidence is available on the effects of various fine particulate matter $\left(\mathrm{PM}_{2.5}\right)$ components on inflammatory cytokines and DNA methylation. We examined whether $16 \mathrm{PM}_{2.5}$ components are associated with changes in four blood biomarkers, that is, tumor necrosis factor- $a$ (TNF- $a$ ), soluble cluster of differentiation 40 ligand (sCD40L), soluble intercellular adhesion molecule-1 (sICAM-1), and fibrinogen, as well as their corresponding DNA methylation levels in a panel of 36 healthy college students in Shanghai, China. We used linear mixed-effect models to evaluate the associations, with controls of potential confounders. We further conducted mediation analysis to evaluate the potential mediation effects of components on inflammatory markers through change in DNA methylation. We observed that several components were consistently associated with TNF- $a$ and fibrinogen as well as their DNA hypomethylation. For example, an interquartile range increase in personal exposure to $\mathrm{PM}_{2.5}$-lead $(\mathrm{Pb})$ was associated with $65.20 \%$ (95\% CI: 37.07, 99.10) increase in TNF- $a$ and 2.66 (95\% CI: 37.07, 99.10) decrease in TNF- $a$ methylation, $30.51 \%$ (95\% CI: 0.72, 69.11) increase in fibrinogen and 1.25 (95\% CI: 0.67, 1.83) decrease in $F 3$ methylation. $\mathrm{PM}_{2.5}$ components were significantly associated with sICAM-1 methylation but not with sICAM-1 protein. DNA methylation mediated $19.89 \%-41.75 \%$ of the elevation in TNF- $a$ expression by various $\mathrm{PM}_{2.5}$ constituents. Our findings provide clues that personal $\mathrm{PM}_{2.5}$ constituents exposure may contribute to increased systemic inflammation through DNA hypomethylation

\footnotetext{
*Corresponding Authors: Phone/fax: +86 (21) 54237908; kanh@fudan.edu.cn. Phone/fax: +86 (21) 54237908; jingcai@fudan.edu.cn.

Supporting Information

The Supporting Information is available free of charge on the ACS Publications website at DOI: 10.1021/acs.est.9b02305.

Primers used for DNA methylation analysis; Materials and Methods; Pearson correlation coefficients; supporting figures and tables (PDF)

The authors declare no competing financial interest.
} 


\section{Graphical Abstract}
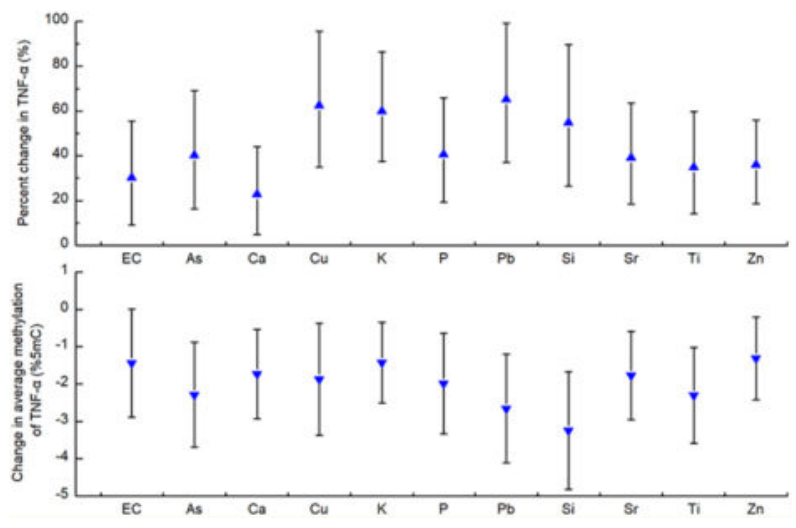

\section{INTRODUCTION}

Extensive epidemiological studies have linked $\mathrm{PM}_{2.5}$ exposure with the hospitalization and mortality caused by various cardiovascular diseases (CVDs). ${ }^{1,2}$ Systemic inflammation has been considered as one common underlying pathological pathway by which $\mathrm{PM}_{2.5}$ affects cardiovascular health. ${ }^{3,4}$ Previous studies found that short-term exposure to total $\mathrm{PM}_{2.5}$ mass may lead to the upregulation of inflammatory cytokines. ${ }^{5}$ However, the involved biological mechanism remains a matter of speculation. Epigenetic alterations can influence the expression of genes without modifying the genetic code, ${ }^{6}$ and typically DNA hypomethylation may be involved in the development of a wide range of CVDs. ${ }^{7}$ Our previous panel study hinted that DNA methylation plays an important role in mediating the effect of total $\mathrm{PM}_{2.5}$ mass exposure on inflammatory pathways. ${ }^{8}$

The cardiovascular effects of integrated $\mathrm{PM}_{2.5}$ have been largely evaluated, ${ }^{9,10}$ but which constituents are most responsible for these effects remain unidentified. This is partially due to the lack of methodology for accurate exposure assessment. Traditionally, $\mathrm{PM}_{2.5}$ exposure assessment relied on fixed monitoring network sites or stationary indoor monitors which usually generate temporally aggregated and averaged data for a certain spatial unit. ${ }^{11}$ However, these methods ignore spatial heterogeneity and the difference of activity-patterns among individuals, which could introduce bias to the results of the health study. The bias thus could be magnified for health effect evaluation of specific $\mathrm{PM}_{2.5}$ constituents, given that $\mathrm{PM}_{2.5}$ composition normally varies with individual and regions. ${ }^{12}$

Therefore, we conducted personal monitoring in a panel of healthy college students in Shanghai, China. We aim to identify the key $\mathrm{PM}_{2.5}$ chemical components responsible for the effects of total $\mathrm{PM}_{2.5}$ exposure on circulating cytokines relevant to systemic inflammation. Moreover, we further explored the mediation effects of specific-gene methylation in the association between inflammatory protein expression and personal $\mathrm{PM}_{2.5}$ constituent exposure. 


\section{MATERIALS AND METHODS}

\section{Study Population and Design.}

This longitudinal panel study was carried out during the period from December 17, 2014 to July 11, 2015. We excluded (1) participants with any diagnosed cardiopulmonary diseases (including asthma, rhinitis et al. $n=2)$; (2) past or current smoker or alcohol addict $(n=0)$; (3) those who are taking any medication/supplements $(n=1)$, and participants that experienced infection within 1 month of baseline physical exam $(n=1)$. Eventually, 36 healthy students from two universities located at downtown area of Shanghai were recruited in this study. To control for the aforementioned potential confounders, all participants were asked to record the information on any use of medications, health conditions, alcohol drinking, and physical activity during the follow ups. During the study period, we scheduled four rounds of repeated measurements for personal exposure and health end points, with at least 2-week interval. The study protocol was approved (IRB No. 2014-TYSQ-09-1) by the Institutional Review Board of the School of Public Health of Fudan University, and written informed consent was obtained from each subject. Detailed information about the study design was described in our previous publication. ${ }^{13}$

\section{Exposure Measurements.}

For each visit, all subjects were instructed to wear a designed sampling vest equipped with HOBO data loggers (Onset Computer Corporation, Pocasset, Massachusetts) and MicroPEM (RTI International, Research Triangle Park, NC, USA). HOBO data loggers were applied to record personal temperature and relative humidity every halfhour. MicroPEM with a 0.50 $( \pm 0.05) \mathrm{L} / \mathrm{min}$ flow rate was used to $\log$ real-time $\mathrm{PM}_{2.5}$ concentrations every $10 \mathrm{~s}$ based on an on-board micronephelometer and collect a Teflon-filtered (FPTPMP325, Zefon, USA) sample through a one-stage $\mathrm{PM}_{2.5}$ impactor. Under such a low flow rate, we collected a $72 \mathrm{~h}$ integrated filter sample for each personal measurement to ensure sufficient amount of loading mass for chemical constitutes analysis.

Fourteen elements were measured via polarized-energy dispersive $\mathrm{X}$-ray fluorescence as described by $\mathrm{Ngo},{ }^{14}$ including arsenic (As), barium (Ba), calcium $(\mathrm{Ca})$, chromium $(\mathrm{Cr})$, copper $(\mathrm{Cu})$, iron $(\mathrm{Fe})$, potassium $(\mathrm{K})$, manganese $(\mathrm{Mn})$, phosphorus $(\mathrm{P})$, lead $(\mathrm{Pb})$, silicon $(\mathrm{Si})$, strontium ( $\mathrm{Sr})$, titanium $(\mathrm{Ti})$, and zinc $(\mathrm{Zn})$. Elemental carbon (EC) concentrations were measured at Columbia University using a multiwavelength optical measurements. ${ }^{15}$ In the absence of measurements of personal organic carbon (OC) due to the limitations of our instruments and technology, we obtained hourly concentrations of OC measured at a fixedsite of the Environmental Science Research Institute (ESRI) of Shanghai which was $0.6 \mathrm{~km}$ away from the residence of our participants. The ambient $\mathrm{OC}$ was then used as a surrogate of OC exposure. Ambient OC concentrations were measured by a semicontinuous OC/EC analyzer (model 4G, Sunset Laboratory, OR, USA). More detailed quality assurance/quality control procedures of component measurements were routinely conducted as described in the Supporting Information SI Materials and Methods and our previous publication. ${ }^{16}$ 


\section{DNA Methylation and Biomarker Measurements.}

For each visit, we collected venous peripheral blood samples after $72 \mathrm{~h}$ personal sampling for DNA methylation and biomarkers measurements. According to our previous studies, ${ }^{8,17}$ we selected four inflammatory proteins, including tumor necrosis factor- $a$ (TNF- $a$ ), intercellular adhesion molecule-1 (ICAM-1), soluble cluster of differentiation 40 ligand (sCD40L), and fibrinogen. The serum levels of TNF- $a$, ICAM-1, and fibrinogen protein were detected by Millipore MILLIPLEX MAP human cytokine/chemokine kit (Millipore Corporation, Billerica, MA, USA). sCD40L expression was determined using enzymelinked immune sorbent assays as in our previous paper. ${ }^{1}$

We measured DNA methylation levels of TNF- $a, I C A M-1$, and $s C D 4 O L$ at the two to five $\mathrm{CpG}$ positions. For fibrinogen protein, we measured DNA methylation levels of $F 3$ instead, as done in previous studies, ${ }^{17,18}$ because fibrinogen does not have corresponding methylation loci to examine. In addition, Bind et al. ${ }^{18}$ documented that $F 3$ hypomethylation may participate in pathways leading to increased fibrinogen in response to air pollution. The locations of the amplified region and each candidate CpG loci are listed in SI Table S1. Information about the primer sequences are provided in SI Table S2. Two milliliters plasma samples were used for DNA extraction using the QIAmp DNA Mini Kit (Qiagen, Hilden, Germany), and the concentration of purified DNA was determined using a ND1000 spectrophotometer (NanoDrop Technologies Inc., Wilmington, DE, USA). We modified aliquots of $300 \mathrm{ng}$ of DNA with sodium bisulfite using the EpiTect Fast DNA Bisulfite Kit (Qiagen, Hilden, Germany) in a final elution volume of $10 \mu \mathrm{L}$ M-Elution buffer. The DNA methylation level was evaluated using highly quantitative bisulfite-PCR pyrosequencing by the PyroMark system (Qiagen, Hilden, Germany). The methylation degree of each CpG dinucleotide was presented as the percentage of methylated cytosines over the sum of methylated and unmethylated cytosines at position $5(\% 5 \mathrm{mC})$. More details of DNA methylation and cytokine measurements have been reported elsewhere ${ }^{8,17}$ and in the SI Materials and Methods.

\section{Statistical Analysis.}

We used a linear mixed-effect (LME) model to estimate association between constituentspecific $\mathrm{PM}_{2.5}$ concentrations and inflammatory markers as well as DNA methylation. All cytokine concentrations were natural log-transformed before statistical analysis to better approximate a normal distribution. In the basic single-constituent model, $\mathrm{PM}_{2.5}$ constituents entered the model as fixed-effect independent variables one at a time, and several covariates including age, gender, body mass index (BMI), $24 \mathrm{~h}$ temperature, $24 \mathrm{~h}$ relative humidity, and season were also incorporated as fixed-effect predictors. In addition, a random participantspecific intercept was introduced to explain the within-subject correlations of repeated measurements. Moreover, a "constituent- $\mathrm{PM}_{2.5}$ joint model" with the adjustment of total $\mathrm{PM}_{2.5}$ mass (72 $\mathrm{h}$ average) was also built to estimate the effects of constituents independent of $\mathrm{PM}_{2.5}$. The Benjamini-Hochberg false discovery rate (FDR) was used for the correction of simultaneous multiple comparisons in dealing with multiple constituent-specific associations estimations. 
All LME models were conducted using the package "Ime4" in R (version 3.5.0, R development Core Team). The effect estimation for blood biomarkers and methylation were expressed as the mean percent changes and the absolute changes with their 95\% confidence intervals (CIs) associated with an interquartile-range (IQR) increase in $\mathrm{PM}_{2.5}$ constituent concentrations. Statistical tests were two-sided, and $P$-value $\$ 0.05$ and $\$ 0.10$ were considered "significant" and "marginal significant", respectively.

We also conducted mediation analyses to evaluate the potential mediation effects of DNA methylation on the association between a component and an inflammatory biomarker. For this analysis, we used the existing "mediation" package in R. Detailed information about the methods and materials are described in SI Materials and Methods.

\section{RESULTS}

\section{Descriptive Statistics.}

Details of the descriptive characteristics of 36 subjects were shown in SI Table S3. Females accounted for nearly $61 \%(22 / 36)$. The average ( \pm standard deviation, SD) age of our participants was $24 \pm 2$ years and the average ( \pm SD) BMI was $21 \pm 3 \mathrm{~kg} / \mathrm{m}^{2}$, respectively (SI Table S3). Results from self-reported questionnaires showed that none of them participated in strenuous physical activity, smoked, drank alcohol, or took medication or supplements during the study period. Because one participant missed the last visit, a total of 143 valid measurements on both exposure and health were eventually collected.

Table 1 provides the summary statistics of personal $\mathrm{PM}_{2.5}$ constituents, temperature, and relative humidity. During the study period, the $72 \mathrm{~h}$ mean $( \pm \mathrm{SD})$ mass concentration of total $\mathrm{PM}_{2.5}$ was $45.73( \pm 31.63) \mu \mathrm{g} / \mathrm{m}^{3}$. Concentrations of $\mathrm{PM}_{2.5}$ constituents vary considerably. Carbonaceous components ( $\mathrm{OC}$ and EC) were the most abundant composition with a mean $( \pm \mathrm{SD})$ of $8.00( \pm 4.92) \mu \mathrm{g} / \mathrm{m}^{3}$ and $6.14( \pm 2.84) \mu \mathrm{g} / \mathrm{m}^{3}$, respectively. Among elements of $\mathrm{PM}_{2.5}$, Fe was the most major component with a mean $( \pm \mathrm{SD})$ of $0.85( \pm 0.45) \mu \mathrm{g} / \mathrm{m}^{3}$, followed by Si with $0.67( \pm 0.0 .35) \mu \mathrm{g} / \mathrm{m}^{3}$. Our findings were comparable to previous studies reported in Hong Kong ${ }^{12}$ and Beijing. ${ }^{19}$ In addition, we observed correlations among constituents varied with constituents but they were all statistically significant at $1 \%$ levels (SI Table S4).

Table 2 provides descriptive statistics for four circulating inflammatory cytokines and average DNA methylation. Mean $( \pm \mathrm{SD})$ concentrations of TNF- $a, \mathrm{sCD} 40 \mathrm{~L}$, fibrinogen, and ICAM-1 were $4.22( \pm 5.27) \mathrm{pg} / \mathrm{mL}, 121.50( \pm 86.61) \mathrm{pg} / \mathrm{mL}, 3.03( \pm 3.58) \mu \mathrm{g} / \mathrm{mL}$, and 172.80 $( \pm 98.31) \mathrm{ng} / \mathrm{mL}$, respectively. ${ }^{8}$ The methylation levels and correlation coefficients of $\mathrm{CpG}$ loci pairs for $T N F-a, I C A M-1, C D 4 O L$ genes have been reported in our previous work, ${ }^{8}$ and the corresponding detailed information for $F 3$ refers to SI Table S5 and SI Figure S1. The mean $( \pm \mathrm{SD}$ ) level of $T N F-a, C D 4 O L, F 3$, and ICAM-1 genes at different CpG loci were $17.28( \pm 6.60) \% 5 \mathrm{mC}, 48.25( \pm 12.46) \% 5 \mathrm{mC}, 3.67( \pm 2.62) \% 5 \mathrm{mC}$, and $3.49( \pm 2.29) \% 5 \mathrm{mC}$, respectively. Although the methylated proportions differed across candidate loci, they were highly correlated with each other (all correlation coefficients ranged from 0.58 to $0.92, P<$ 0.05). They may share most of the same functional complexes and traits; we hence introduced the average methylation levels across sites into the model. The correlation 
coefficients for the four proteins versus the DNA methylation levels at corresponding upstream candidate $\mathrm{CpG}$ sites are shown in SI Table S6. Significant negative correlations were found between TNF- $a$ methylation and TNF- $a$ protein, between F3 methylation and fibrinogen protein.

\section{Regression Results.}

The effect on four circulating inflammatory biomarkers varied with constituents and with biomarkers. The percent changes in four inflammatory proteins per an IQR increase in specific $16 \mathrm{PM}_{2.5}$ constituents' concentrations are illustrated in Figure 1. We observed significant positive associations of all $\mathrm{PM}_{2.5}$ chemical components with at least one circulating biomarker. sICAM-1 protein was not associated with any constituent; in contrast, TNF-a protein was significantly correlated with all $\mathrm{PM}_{2.5}$ constituents. Especially, an IQR increase in personal exposure to $\mathrm{Pb}$ was associated with increases of $42.43 \%$ (95\% confidence interval (CI): 4.27, 94.57) $(P=0.03)$ and $65.20 \%(95 \%$ CI: 37.07, 99.10) $(P<$ $0.01)$ in SCD40L and TNF- $a$, respectively. An IQR elevation in personal exposure to $\mathrm{Si}$ was associated with increases of $44.46 \%$ (95\% CI: 16.12, 79.71) in fibrinogen.

Figure 2 presents the changes in DNA methylation associated with an increase in the $72 \mathrm{~h}$ average concentration of $\mathrm{PM}_{2.5}$ constituents. We observed a significant elevation in all 16 components associated with the immediate decrease in at least one circulating inflammatory methylation, except for $\mathrm{Cr}$ which was negatively linked with the $S I C A M-1$ methylation with marginal significance $(P=0.10)$. For example, an IQR increase in personal exposure to $\mathrm{K}$ and $\mathrm{Pb}$ was associated with decreases of 1.28 (95\% CI: $0.45,2.11)(P<0.01)$ and 1.25 (95\%CI: $0.67,1.84)(P<0.01)$ in CD40L methylation and $F 3$ methylation $(\% 5 \mathrm{mC})$, respectively. Si was associated with both $1.21(95 \% \mathrm{CI}: 0.65,1.76)(\mathrm{P}<0.01)$ and 3.25 $(95 \% \mathrm{CI}: 1.67,4.82)(P<0.01)$ decrease in $s I C A M-1$ and $T N F-a$ methylation $(\% 5 \mathrm{mC})$, respectively.

Notably, after correcting for multiple comparisons (Table S7), we found robust associations between $\mathrm{PM}_{2.5}$ constituents and TNF- $a$ cytokines; while, the important associations between $\mathrm{PM}_{2.5}$ constituents and $\mathrm{SCD} 40 \mathrm{~L}$ cytokines as well as $C D 4 O L$ methylation turned to be borderline significant or insignificant. The magnitude of the associations between $\mathrm{PM}_{2.5}$ constituents and fibrinogen, ICAM-1 cytokines, and DNA methylation was slightly attenuated, and the $95 \%$ CIs became wider. Furthermore, except for the sCD40L protein, the significant associations between $\mathrm{PM}_{2.5}$ constituents and other inflammation markers as well as the methylation of candidate genes did not substantially change in the constituent- $\mathrm{PM}_{2.5}$ joint model (SI Figures S2 and S3).

The average methylation level of TNF- $a$ (Pearson $\mathrm{r}=-0.46, P<0.01$ ) and $F 3$ (Pearson $\mathrm{r}=$ $-0.21, P<0.05)$ were significantly inversed with their corresponding proteins. These relationships suggested that hypomethylation in $T N F-a$ and $F 3$ genes has the potential to indirectly mediate the effects of the $\mathrm{PM}_{2.5}$ constituent on the protein. Table 3 and SI Table S8 show the results of mediation analysis. The mediated effects of TNF- $a$ methylation in the associations between $\mathrm{PM}_{2.5}$ constituents and TNF $a$ protein varied greatly among various constituents. Reduced methylation of $T N F-a$ significantly mediated from $19.89 \%(\mathrm{Cu})(\mathrm{P}=$ $0.03)$ to $41.75 \%(\mathrm{Ca})(P=0.05)$ of the association between personal exposure to $\mathrm{PM}_{2.5}$ 
components and the elevation in TNF- $a$ protein. However, we did not observe a significant mediation effect of $F 3$ methylation $(P>0.10)$.

\section{DISCUSSION}

Previously, we have reported positive associations between integrated $\mathrm{PM}_{2.5}$ exposure and the levels of inflammatory cytokines in this group of participants. ${ }^{8}$ Our current results identified that specific constituents of $\mathrm{PM}_{2.5}$ exposure substantially contributed to these associations, which has implications for developing air pollution abatement strategies to maximize public health benefits. Moreover, this study linked $\mathrm{PM}_{2.5}$ constituents to inflammation methylation on genes related to inflammation pathways, and the mediation analysis provided further insight into the potential importance of the association between $\mathrm{PM}_{2.5}$ exposure and gene-specific methylation.

Systemic inflammation has been suggested as a common underlying pathway of cardiovascular diseases caused by $\mathrm{PM}_{2.5}$ exposure. ${ }^{20}$ In this study, we selected an informative set of circulatory cytokines (TNF- $a$, sICAM-1, sCD40L, and fibrinogen) which are well-established indicators of systemic inflammation and could predict cardiovascular disease risk. ${ }^{21,22}$ These biomarkers have been linked with $\mathrm{PM}_{2.5}$ concentrations, ${ }^{23}$ however, the results are not consistent. ${ }^{24}$ The inconsistency of the observations may be partially due to the outdoor fixed-site measurements that were used to assess exposure in these studies which may cause exposure misclassification. ${ }^{25}$ In our study, personal sampling was conducted to minimize the bias. Our observation that TNF- $a$ and SCD40L were associated with a set of $\mathrm{PM}_{2.5}$ components further confirmed our previous findings of acute inflammation following personal exposure to total $\mathrm{PM}_{2.5}{ }^{8}$ In contrast, none of components were identified to be significantly associated with sICAM-1. This suggests that other components (such as ion fraction) that were not examined in this study may be responsible for sICAM-1 expression; that is, Bind et al. ${ }^{26}$ observed that exposure to sulfate could cause sICAM-1 protein overexpression.

We found consistent positive associations between the following $\mathrm{PM}_{2.5}$ components and selected inflammatory biomarkers in both the basic single-constituent model and the constituent-PM 2.5 joint model. EC was found to be associated with $\mathrm{SCD} 40 \mathrm{~L}$, fibrinogen, and TNF- $a$ increase. The effect on TNF- $a$ and fibrinogen remained robust after accounting for multiple comparisons and adjustment for $\mathrm{PM}_{2.5}$, supporting the finding from our prior study in a panel of 28 urban residents in Shanghai. ${ }^{23}$ Similar results were reported elsewhere. ${ }^{27-29}$ In the metropolis cities, EC is a strong marker of vehicle exhaust. Lall et al. found that 2.8 $\mu \mathrm{g} / \mathrm{m}^{3}$ increased in traffic-related $\mathrm{PM}_{2.5}$ exposures were positively associated with same day total cardiovascular admissions ( $\mathrm{RR}=1.041 ; 95 \% \mathrm{CI}, 1.005-1.077)$ across disease-specific subcategories: stroke and heart failure. ${ }^{30}$ Thus, our results suggest that the traffic emission might be partly responsible for the influence of $\mathrm{PM}_{2.5}$ exposure on cardiovascular system disease through inflammatory response.

Although crustal elements only account for a small portion of $\mathrm{PM}_{2.5}$ mass, five of them were observed to have stronger influences on inflammatory biomarkers, including $\mathrm{K}, \mathrm{Ca}, \mathrm{P}, \mathrm{Si}$, and Sr. Similar effects were also found in transition metals $(\mathrm{Cu}$ and $\mathrm{Ti})$ and heavy metals (As 
and $\mathrm{Pb}$ ). Among these elements, $\mathrm{K}$ and $\mathrm{P}$ could be traced to biomass burning, $\mathrm{Pb}$ and $\mathrm{As}$ are widely recognized as markers of industry sources and mobile combustion, ${ }^{31}$ and $\mathrm{Ca}, \mathrm{Sr}$, and Si mostly are attributed to emissions from mixed sources of construction dust, soil, and industry processes. ${ }^{32,33}$ Our analyses are in line with the previous findings. For example, Wu et al. found that a significant increase in fibrinogen is associated with dust and soil-source high loading of $\mathrm{Ca}, \mathrm{Ba}, \mathrm{Sr}$ and $\mathrm{Ti}$ in Beijing among a panel of 40 healthy university students. 34 Toxicological and pathological studies documented significant associations of $\mathrm{Cu}, \mathrm{Ca}, \mathrm{K}$, $\mathrm{Si}$, and $\mathrm{Ti}$ with inflammatory responses, and these components may possess the ability to induce toxic effects in a cardiopulmonary system. ${ }^{35,36}$ Rich et al. reported that increased acute cardiovascular hospitalization rates were associated with increased concentrations of road dust, which showed high explained variations and concentrations for $\mathrm{Si}, \mathrm{Ca}$, $\mathrm{Ti}$, and $\mathrm{Cu}$. 37,38 Thus, our findings provide evidence that exposure to the aforementioned trace elements could increase cardiovascular risks. These results also highlight that specific sources of pollution (i.e., dust, motor vehicles, biomass combustion, and industry) should be of particular concern.

It is not clear how systemic inflammation and adverse cardiovascular outcomes are triggered by $\mathrm{PM}_{2.5}$ exposure. A recent research has identified that DNA methylation can be a potential biological mechanism to explain adverse health effects from air pollution. ${ }^{39}$ This hypothesis could be supported by our observation that a similar set of compositions was associated with hypomethylation of genes coding $T N F-a$ and $F 3$ proteins. Our mediation analysis further confirmed that decreased $T N F-a$ methylation potentially mediated the elevated level of the $T N F-a$ protein of several $\mathrm{PM}_{2.5}$ constituent exposures, including $\mathrm{EC}, \mathrm{As}, \mathrm{Ca}, \mathrm{Cu}, \mathrm{K}, \mathrm{P}, \mathrm{Pb}$, $\mathrm{Si}, \mathrm{Sr}, \mathrm{Ti}$, and $\mathrm{Zn}$. Especially, the mediation effects for these compositions were more than $30 \%$. However, the mediated effect of $F 3$ methylation was not significant, which may be due to the much smaller variation of $F 3$ methylation (2.62 vs 6.60 for $T N F$ - $a$ methylation). We did not observe any mediation effects of sCD40L and sICAM-1, which may be impacted by other biological processes.

The current study has several strengths. First, this longitudinal panel study measured $\mathrm{PM}_{2.5}$ chemical components in individual levels, which offers an accurate exposure assessment. Second, this study simultaneously evaluated the variation of circulating gene-specific methylation and the expression of the associated inflammatory cytokine after $\mathrm{PM}_{2.5}$ constituent exposure, which provides a unique opportunity for a preliminary assessment of the potential mediation of methylation epigenetics in the cardiovascular effects of $\mathrm{PM}_{2.5}$. Third, all the participants were healthy nonsmoking young college students in the present study, which minimizes the impacts of several confounders, such as unhealthy lifestyle, medication use, chronic disease, ect.

Several limitations still exist in our study. First, because the personal exposure measurement is expensive and burdensome, we only recruited 36 participants, which somewhat limited our statistical power and precision. Second, OC concentrations monitored at a fixed-site were used to substitute personal OC exposure levels, which may slightly attenuate the accuracy of assessment of the relationships between the OC fraction and the biomarkers. Third, we only obtained the $72 \mathrm{~h}$ concentrations of personal $\mathrm{PM}_{2.5}$ constituent exposure, other exposure time windows (e.g., 24 h) thus cannot be tested in this study. Finally, we did 
not evaluate the effects of ions (e.g., $\left.\mathrm{SO}_{4}{ }^{2-}, \mathrm{NO}_{3}{ }^{-}\right)$and gaseous air pollutants $\left(\mathrm{SO}_{2}, \mathrm{NO}_{2}\right.$ and $\mathrm{O}_{3}$ ), which might also influence DNA methylation and the protein levels, due to the limitation of instruments.

In summary, this longitudinal panel study highlighted that $T N F-a$ hypomethylation might play a modest mediate role in the effects of personal exposure to carbon and trace element components exposure (EC, As, $\mathrm{Ca}, \mathrm{Cu}, \mathrm{K}, \mathrm{P}, \mathrm{Pb}, \mathrm{Si}, \mathrm{Sr}, \mathrm{Ti}$, and $\mathrm{Zn}$ ) on increased TNF- $a$ expression. Our results provide evidence for the speculation that methylation epigenetic regulation may be one of the key physiological mechanisms linking $\mathrm{PM}_{2.5}$ exposure and adverse cardiovascular outcome. More epidemiological and toxicological studies with comprehensive analysis of the exposure, biomarker variables, and organ and tissue responses to specific $\mathrm{PM}_{2.5}$ constituents and mixtures are required to replicate our findings and to decipher the biological mechanism in the future.

\section{Supplementary Material}

Refer to Web version on PubMed Central for supplementary material.

\section{ACKNOWLEDGMENTS}

The study was supported by the National Key Research and Development Program of China (2016YFC0206504), National Natural Science Foundation of China (91543114), and the Open Foundation of Shanghai Key Laboratory of Meteorological and Health (QXJK201802).

\section{REFERENCES}

(1). Requia WJ; Adams MD; Arain A; Papatheodorou S; Koutrakis P; Mahmoud M Global Association of Air Pollution and Cardiorespiratory Diseases: A Systematic Review, MetaAnalysis, and Investigation of Modifier Variables. Am. J. Public Health 2018, 108 (S2), S123S130. [PubMed: 29072932]

(2). Schwartz J; Bind MA; Koutrakis P Estimating Causal Effects of Local Air Pollution on Daily Deaths: Effect of Low Levels. Environ. Health Perspect 2017, 125 (1), 23-29. [PubMed: 27203595]

(3). Chuang KJ; Chan CC; Su TC; Lee CT; Tang CS The effect of urban air pollution on inflammation, oxidative stress, coagulation, and autonomic dysfunction in young adults. Am. J. Respir. Crit. Care Med 2007, 176 (4), 370-6. [PubMed: 17463411]

(4). Aung N; Sanghvi MM; Zemrak F; Lee AM; Cooper JA; Paiva JM; Thomson RJ; Fung K; Khanji MY; Lukaschuk E; Carapella V; Kim YJ; Munroe PB; Piechnik SK; Neubauer S; Petersen SE Association Between Ambient Air Pollution and Cardiac Morpho-Functional Phenotypes: Insights From the UK Biobank Population Imaging Study. Circulation 2018, 138 (20), 21752186. [PubMed: 30524134]

(5). Cheng H; Davis DA; Hasheminassab S; Sioutas C; Morgan TE; Finch CE Urban traffic-derived nanoparticulate matter reduces neurite outgrowth via TNFalpha in vitro. J. Neuroinflammation 2016, 13, 19. [PubMed: 26810976]

(6). Eckhardt F; Lewin J; Cortese R; Rakyan VK; Attwood J; Burger M; Burton J; Cox TV; Davies R; Down TA; Haefliger C; Horton R; Howe K; Jackson DK; Kunde J; Koenig C; Liddle J; Niblett D; Otto T; Pettett R; Seemann S; Thompson C; West T; Rogers J; Olek A; Berlin K; Beck S DNA methylation profiling of human chromosomes 6, 20 and 22. Nat. Genet 2006, 38 (12), 1378-85. [PubMed: 17072317]

(7). Baccarelli A; Ghosh S Environmental exposures, epigenetics and cardiovascular disease. Curr. Opin. Clin. Nutr. Metab. Care 2012, 15 (4), 323-9. [PubMed: 22669047] 
(8). Wang C; Chen R; Shi M; Cai J; Shi J; Yang C; Li H; Lin Z; Meng X; Liu C; Niu Y; Xia Y; Zhao Z; Kan H; Weinberg CR Possible Mediation by Methylation in Acute Inflammation Following Personal Exposure to Fine Particulate Air Pollution. Am. J. Epidemiol 2018, 187 (3), 484-493. [PubMed: 29020142]

(9). Bonjour S; Adair-Rohani H; Wolf J; Bruce NG; Mehta S; Pruss-Ustun A; Lahiff M; Rehfuess EA; Mishra V; Smith KR Solid fuel use for household cooking: country and regional estimates for 1980-2010. Environ. Health Perspect 2013, 121 (7), 784-90. [PubMed: 23674502]

(10). Cohen AJ; Brauer M; Burnett R; Anderson HR; Frostad J; Estep K; Balakrishnan K; Brunekreef B; Dandona L; Dandona R; Feigin V; Freedman G; Hubbell B; Jobling A; Kan H; Knibbs L; Liu Y; Martin R; Morawska L; Pope CA; Shin H; Straif K; Shaddick G; Thomas M; van Dingenen R; van Donkelaar A; Vos T; Murray CJL; Forouzanfar MH Estimates and 25-year trends of the global burden of disease attributable to ambient air pollution: an analysis of data from the Global Burden of Diseases Study 2015. Lancet 2017, 389 (10082), 1907-1918. [PubMed: 28408086]

(11). Steinle S; Reis S; Sabel CE Quantifying human exposure to air pollution-moving from static monitoring to spatio-temporally resolved personal exposure assessment. Sci. Total Environ 2013, 443, 184-93. [PubMed: 23183229]

(12). Chen XC; Chow JC; Ward TJ; Cao JJ; Lee SC; Watson JG; Lau NC; Yim SHL; Ho KF Estimation of personal exposure to fine particles (PM2.5) of ambient origin for healthy adults in Hong Kong. Sci. Total Environ 2019, 654, 514-524. [PubMed: 30447590]

(13). Wang C; Cai J; Chen R; Shi J; Yang C; Li H; Lin Z; Meng X; Liu C; Niu Y; Xia Y; Zhao Z; Li $\mathrm{W}$; Kan $\mathrm{H}$ Personal exposure to fine particulate matter, lung function and serum club cell secretory protein (Clara). Environ. Pollut 2017, 225, 450-455. [PubMed: 28284549]

(14). Ngo NS; Gatari M; Yan B; Chillrud SN; Bouhamam K; Kinney PL Occupational exposure to roadway emissions and inside informal settlements in sub-Saharan Africa: A pilot study in Nairobi, Kenya. Atmos. Environ 2015, 111, 179-184.

(15). Yan B; Kennedy D; Miller RL; Cowin JP; Jung KH; Perzanowski M; Balletta M; Perera FP; Kinney PL; Chillrud SN Validating a nondestructive optical method for apportioning colored particulate matter into black carbon and additional components. Atmos. Environ 2011, 45 (39), 7478-7486.

(16). Chen C; Cai J; Wang C; Shi J; Chen R; Yang C; Li H; Lin Z; Meng X; Zhao A; Liu C; Niu Y; Xia Y; Peng L; Zhao Z; Chillrud S; Yan B; Kan H Estimation of personal PM2.5 and BC exposure by a modeling approach - Results of a panel study in Shanghai, China. Environ. Int 2018, 118, 194-202. [PubMed: 29885590]

(17). Chen R; Meng X; Zhao A; Wang C; Yang C; Li H; Cai J; Zhao Z; Kan H DNA hypomethylation and its mediation in the effects of fine particulate air pollution on cardiovascular biomarkers: A randomized crossover trial. Environ. Int 2016, 94, 614-619. [PubMed: 27397927]

(18). Bind MA; Baccarelli A; Zanobetti A; Tarantini L; Suh H; Vokonas P; Schwartz J Air Pollution and Markers of Coagulation, Inflammation, and Endothelial Function. Epidemiology 2012, 23 (2), 332-340. [PubMed: 22237295]

(19). Shang J; Khuzestani RB; Tian J; Schauer JJ; Hua J; Zhang Y; Cai T; Fang D; An J; Zhang Y Chemical characterization and source apportionment of PM2.5 personal exposure of two cohorts living in urban and suburban Beijing. Environ. Pollut 2019, 246, 225-236. [PubMed: 30557796]

(20). Panasevich S; Leander K; Rosenlund M; Ljungman P; Bellander T; de Faire U; Pershagen G; Nyberg F Associations of long- and short-term air pollution exposure with markers of inflammation and coagulation in a population sample. Occup. Environ. Med 2009, 66 (11), 74753. [PubMed: 19687019]

(21). Sarzi-Puttini P; Atzeni F; Doria A; Iaccarino L; Turiel M Tumor necrosis factor-a, biologic agents and cardiovascular risk. Lupus 2005, 14 (9), 780-84. [PubMed: 16218487]

(22). Wu S; Deng F; Wei H; Huang J; Wang H; Shima M; Wang X; Qin Y; Zheng C; Hao Y; Guo X Chemical constituents of ambient particulate air pollution and biomarkers of inflammation, coagulation and homocysteine in healthy adults: a prospective panel study. Part. Fibre Toxicol 2012, 9 (1), 49. [PubMed: 23231781]

(23). Liu C; Cai J; Qiao L; Wang H; Xu W; Li H; Zhao Z; Chen R; Kan H The Acute Effects of Fine Particulate Matter Constituents on Blood Inflammation and Coagulation. Environ. Sci. Technol 2017, 51 (14), 8128-8137. [PubMed: 28621946] 
(24). Brauner EV; Moller P; Barregard L; Dragsted LO; Glasius M; Wahlin P; Vinzents P; RaaschouNielsen O; Loft S Exposure to ambient concentrations of particulate air pollution does not influence vascular function or inflammatory pathways in young healthy individuals. Part. Fibre Toxicol 2008, 5, 13. [PubMed: 18837984]

(25). Goldman GT; Mulholland JA; Russell AG; Strickland MJ; Klein M; Waller LA; Tolbert PE Impact of exposure measurement error in air pollution epidemiology: effect of error type in timeseries studies. Environ. Health 2011, 10 (1), 61. [PubMed: 21696612]

(26). Bind MA; Lepeule J; Zanobetti A; Gasparrini A; Baccarelli A; Coull BA; Tarantini L; Vokonas PS; Koutrakis P; Schwartz J Air pollution and gene-specific methylation in the Normative Aging Study: association, effect modification, and mediation analysis. Epigenetics 2014, 9 (3), 448-58. [PubMed: 24385016]

(27). Croft DP; Cameron SJ; Morrell CN; Lowenstein CJ; Ling F; Zareba W; Hopke PK; Utell MJ; Thurston SW; Thevenet-Morrison K; Evans KA; Chalupa D; Rich DQ Associations between ambient wood smoke and other particulate pollutants and biomarkers of systemic inflammation, coagulation and thrombosis in cardiac patients. Environ. Res 2017, 154, 352-361. [PubMed: 28167447]

(28). Cakmak S; Dales RE; Vida CB Components of particulate air pollution and mortality in Chile. Int. J. Occup. Environ. Health 2009, 15 (2), 152-8. [PubMed: 19496481]

(29). Ostro B; Feng WY; Broadwin R; Green S; Lipsett M The effects of components of fine particulate air pollution on mortality in california: results from CALFINE. Environ. Health Perspect 2007, 115 (1), 13-9. [PubMed: 17366813]

(30). Lall R; Ito K; Thurston GD Distributed lag analyses of daily hospital admissions and sourceapportioned fine particle air pollution. Environ. Health Perspect 2011, 119 (4), 455-60. [PubMed: 21172759]

(31). Sun Y; Zhuang G; Wang Y; Han L; Guo J; Dan M; Zhang W; Wang Z; Hao Z The air-borne particulate pollution in Beijing-concentration, composition, distribution and sources. Atmos. Environ 2004, 38 (35), 5991-6004.

(32). Song Y; Tang X; Xie S; Zhang Y; Wei Y; Zhang M; Zeng L; Lu S Source apportionment of PM2.5 in Beijing in 2004. J. Hazard. Mater 2007, 146 (1-2), 124-30. [PubMed: 17208371]

(33). Sarnat JA; Marmur A; Klein M; Kim E; Russell AG; Sarnat SE; Mulholland JA; Hopke PK; Tolbert PE Fine particle sources and cardiorespiratory morbidity: an application of chemical mass balance and factor analytical source-apportionment methods. Environ. Health Perspect 2008, 116 (4), 459-66. [PubMed: 18414627]

(34). Wu S; Deng F; Wei H; Huang J; Wang X; Hao Y; Zheng C; Qin Y; Lv H; Shima M; Guo X Association of cardiopulmonary health effects with source-appointed ambient fine particulate in Beijing, China: a combined analysis from the Healthy Volunteer Natural Relocation (HVNR) study. Environ. Sci. Technol 2014, 48 (6), 3438-48. [PubMed: 24521469]

(35). Gurgueira SA; Lawrence J; Coull B; Murthy GK; Gonzalez-Flecha B Rapid increases in the steady-state concentration of reactive oxygen species in the lungs and heart after particulate air pollution inhalation. Environ. Health Perspect 2002, 110 (8), 749-755.

(36). Hetland RB; Cassee FR; Refsnes M; Schwarze PE; Låg M; Boere AJF; Dybing E Release of inflammatory cytokines, cell toxicity and apoptosis in epithelial lung cells after exposure to ambient air particles of different size fractions. Toxicol. In Vitro 2004, 18 (2), 203-212. [PubMed: 14757111]

(37). Squizzato S; Masiol M; Rich DQ; Hopke PK A longterm source apportionment of PM2.5 in New York State during 2005-2016. Atmos. Environ 2018, 192, 35-47.

(38). Rich DQ; Zhang W; Lin S; Squizzato S; Thurston SW; van Wijngaarden E; Croft D; Masiol M; Hopke PK Triggering of cardiovascular hospital admissions by source specific fine particle concentrations in urban centers of New York State. Environ. Int 2019, 126, 387-394. [PubMed: 30826617]

(39). Bollati V; Baccarelli A Environmental epigenetics. Heredity 2010, 105 (1), 105-12. [PubMed: 20179736] 

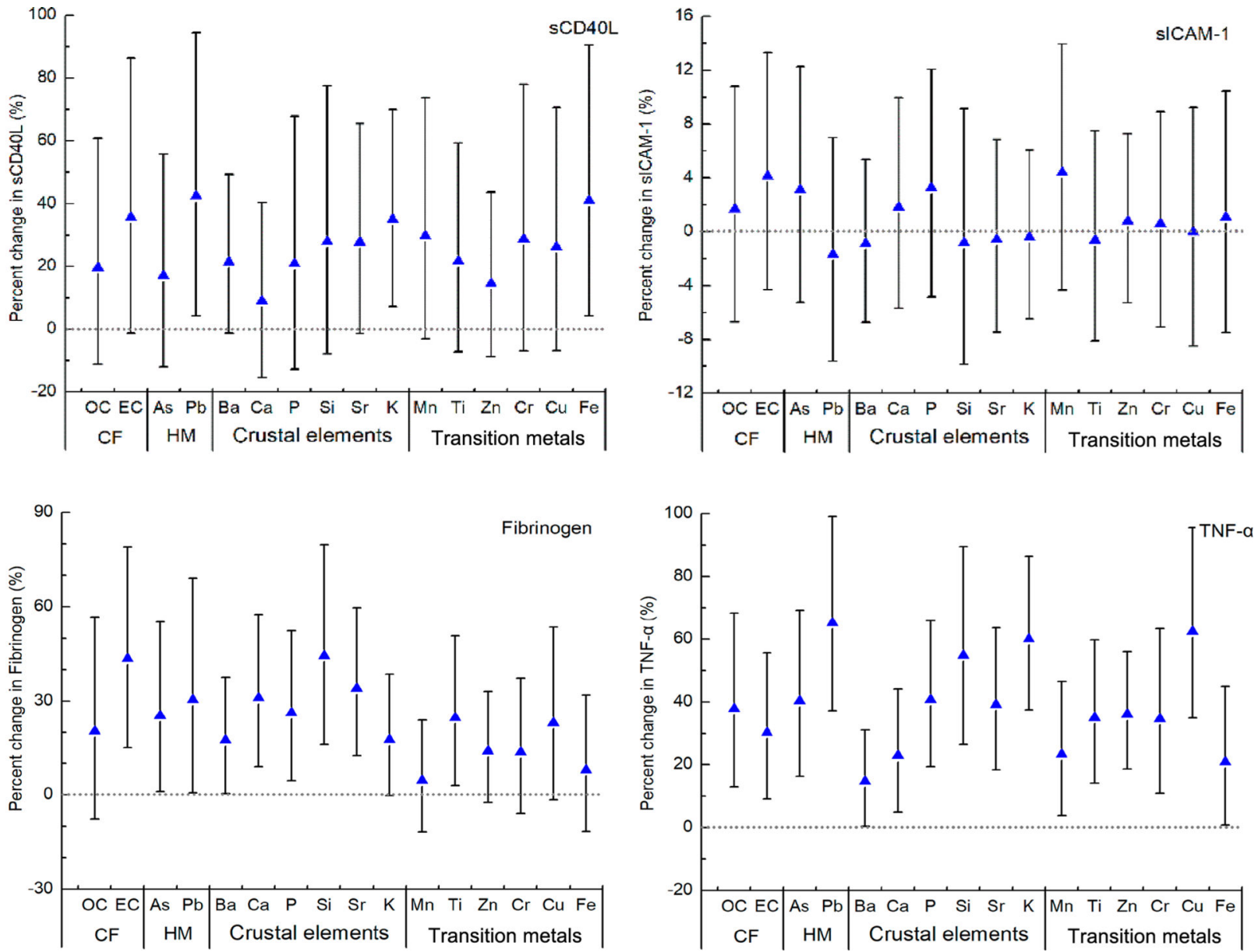

Figure 1.

Percent changes in four inflammation proteins associated with an interquartile range increase in personal $72 \mathrm{~h}$ average concentrations of $\mathrm{PM}_{2.5}$ constituents in the singleconstituent model. Abbreviations: TNF- $a$, tumor necrosis factor alpha; sICAM-1, soluble intercellular adhesion molecule-1; sCD40L, soluble cluster of differentiation 40 (CD40) ligand; $\mathrm{CF}$, carbonaceous fractions; HM, heavy metals. 

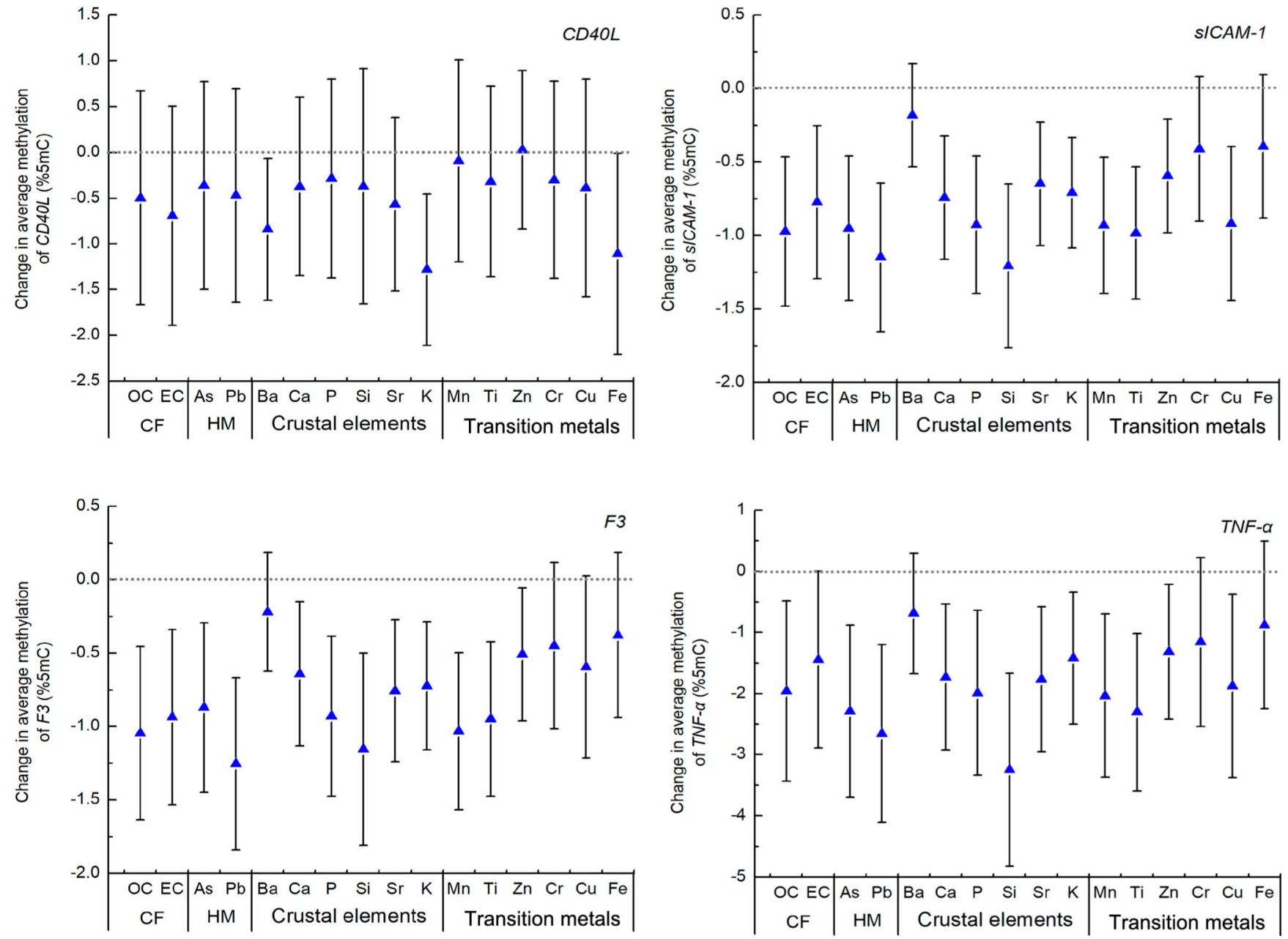

Figure 2.

Changes in DNA methylation $(5 \% \mathrm{mC})$ of four inflammation genes associated with an interquartile range increase in personal $72 \mathrm{~h}$ average concentrations of $\mathrm{PM}_{2.5}$ constituents in the single-constituent model. Abbreviations: TNF-a, tumor necrosis factor alpha; sICAM-1, soluble intercellular adhesion molecule-1; CD4OL, cluster of differentiation 40 (CD40) ligand; F3: tissue factor; $\mathrm{CF}$, carbonaceous fractions; $\mathrm{HM}$, heavy metals. 


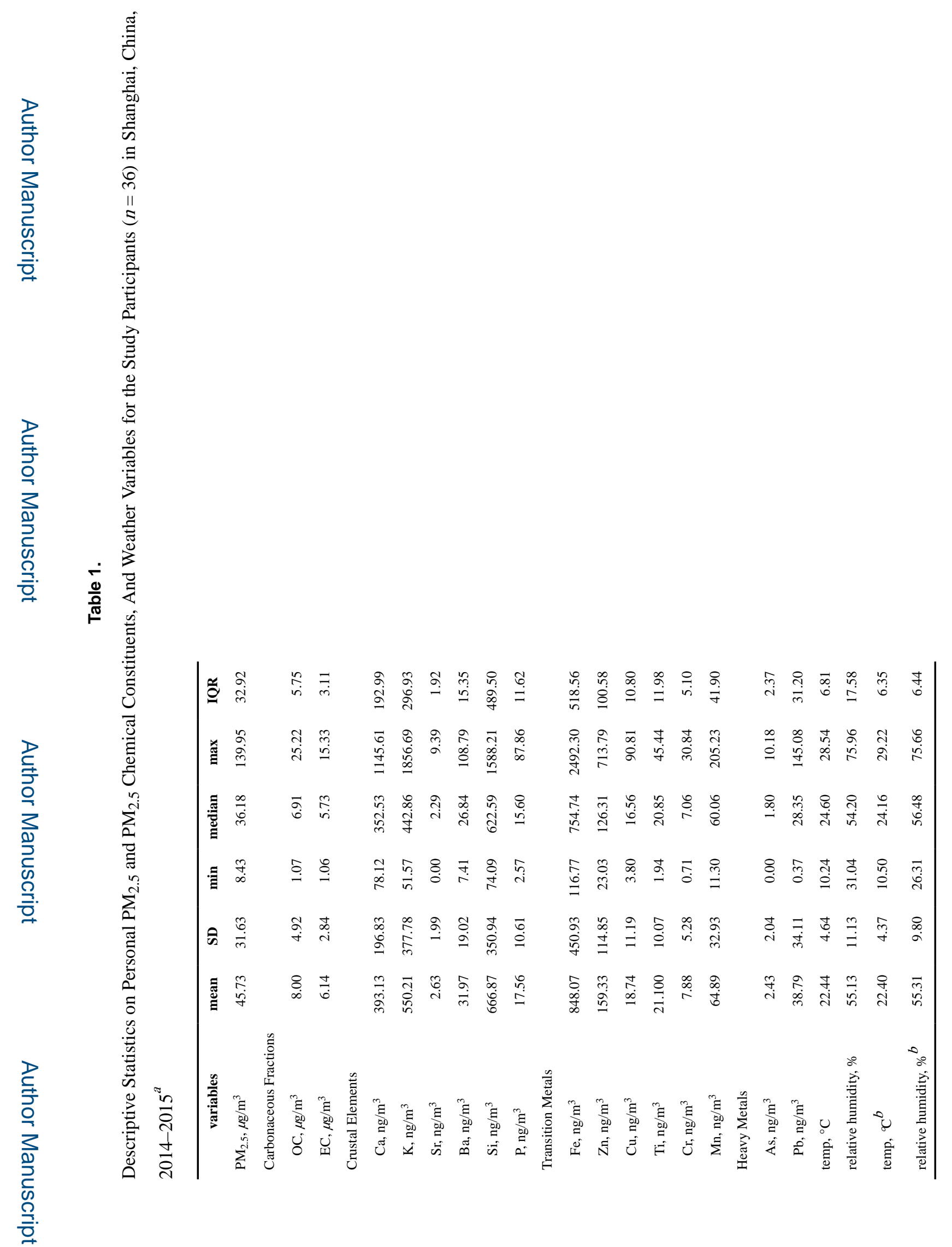

Environ Sci Technol. Author manuscript; available in PMC 2020 March 24. 


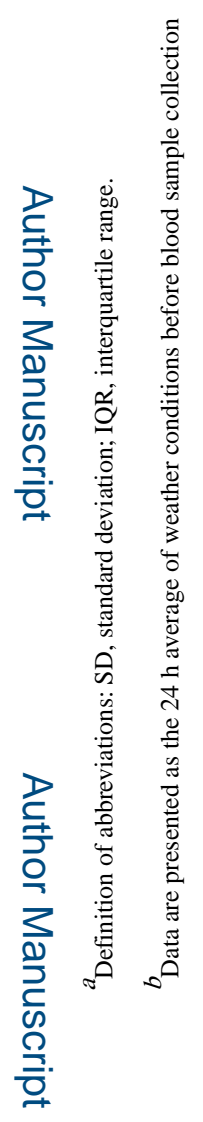

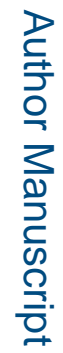

롤

Environ Sci Technol. Author manuscript; available in PMC 2020 March 24. 
Table 2.

Descriptive Statistics on Inflammation-Related DNA Methylations and Cytokines for the Study Participants ( $n$ =36) in Shanghai, China, 2014-2015

\begin{tabular}{llllll}
\hline \multicolumn{1}{c}{ variables } & mean & SD & min & median & max \\
Cytokines & & & & & \\
TNF- $a, \mathrm{pg} / \mathrm{mL}$ & 4.22 & 5.27 & 0.66 & 2.44 & 38.88 \\
ICAM-1, ng/mL & 172.80 & 98.31 & 24.92 & 143.80 & 574.40 \\
sCD40L, pg/mL & 121.50 & 86.61 & 0.33 & 111.00 & 372.00 \\
fibrinogen, $\mu \mathrm{g} / \mathrm{mL}$ & 3.03 & 3.58 & 0.88 & 1.88 & 26.83 \\
Gene-Specific Methylation & & & & & \\
TNF- $a$ methylation, \%5mC & 17.28 & 6.60 & 6.61 & 15.14 & 35.43 \\
ICAM-1 methylation, \%5mC & 3.49 & 2.29 & 0.00 & 2.91 & 8.88 \\
CD4OL methylation, \%5mC & 48.25 & 12.46 & 25.73 & 55.71 & 63.64 \\
F3 methylation, \%5mC & 3.67 & 2.62 & 0.00 & 2.92 & 9.40 \\
\hline
\end{tabular}

aDefinition of abbreviations: SD, standard deviation; TNF- $a, T N F$ encoding tumor necrosis factor- $a$; ICAM-1, ICAM1 encoding intercellular adhesion molecule-1; sCD40L, CD4OLG encoding soluble cluster of differentiation 40 (CD40) ligand; F3, F3 encoding tissue factor. 
Table 3.

Mediated Effects of TNF-a Methylation in the Associations between Personal $\mathrm{PM}_{2.5}$ Compositions Exposure and TNF- $a$ Protein

\begin{tabular}{ccccc}
\hline \multicolumn{5}{c}{ PM $_{\mathbf{2 . 5}}$ constituents $\rightarrow \boldsymbol{T N F}$ - $\boldsymbol{a}$ methylation $\rightarrow$ TNF- $\boldsymbol{a}$ protein } \\
\hline pathway & mean (\%) & $\mathbf{9 5 \%}$ CI lower (\%) & $\mathbf{9 5 \%}$ CI upper (\%) & $\boldsymbol{P}$-value \\
$\mathrm{EC}$ & 29.34 & -7.90 & 76.00 & 0.10 \\
$\mathrm{As}$ & 33.50 & 9.30 & 69.00 & 0.02 \\
$\mathrm{Ca}$ & 41.75 & -0.53 & 139.00 & 0.05 \\
$\mathrm{Cu}$ & 19.89 & 3.89 & 39.00 & 0.03 \\
$\mathrm{~K}$ & 27.00 & 13.10 & 48.00 & 0.00 \\
$\mathrm{P}$ & 26.53 & 6.84 & 48.00 & 0.02 \\
$\mathrm{~Pb}$ & 25.21 & 9.88 & 48.00 & 0.00 \\
$\mathrm{Si}$ & 34.70 & 17.50 & 59.00 & 0.00 \\
$\mathrm{Sr}$ & 27.18 & 6.27 & 57.00 & 0.01 \\
$\mathrm{Ti}$ & 32.40 & 12.10 & 74.00 & 0.00 \\
$\mathrm{Zn}$ & 20.27 & 0.43 & 40.00 & 0.04 \\
\hline
\end{tabular}

